\title{
Trabalhando com textos no ensino superior
}

\author{
Magda Floriana Damiani \\ Universidade Federal de Pelotas, Brasil
}

\section{Resumo}

Este artigo tem por objetivo apresentar, discutir e avaliar uma proposta de atividade didática no ensino superior, baseada principalmente na leitura e discussão de textos e demandando uma postura ativa por parte dos estudantes. Tal proposta foi formulada como uma alternativa às atividades didáticas tradicionais, que geralmente utilizam os textos apenas como fontes de informações. Ela está embasada na Psicologia Sócio-Histórica e vem sendo desenvolvida na Universidade Federal de Pelotas (Brasil). Foi analisada por meio de avaliações escritas que colheram as opiniões de estudantes de uma turma de Pedagogia sobre tal proposta. As avaliações sofreram um processo de análise temática e indicam que a proposta, apesar de algumas críticas (relativas, principalmente, ao esforço necessário para desenvolver as tarefas), foi considerada bem sucedida. As estudantes apontaram que, por meio das atividades realizadas, puderam: compreender de maneira mais profunda os textos lidos e internalizar seu conteúdo de forma mais eficiente, estabelecer interconexões com outros conteúdos anteriormente trabalhados e/ou com experiências vivenciadas e refletir sobre o que aprenderam, além de desenvolver e aprimorar suas habilidades de expressão escrita e outras relacionadas aos processos de pensamento.

Palavras-chave

Trabalho com textos; Ensino superior; Aprendizagem; Psicologia SócioHistórica

\section{Introdução e justificativa}

A pesquisa aqui relatada teve por objetivo analisar e avaliar os efeitos, sobre universitários, de uma prática pedagógica baseada na leitura e 
discussão de textos. Tal prática foi desenvolvida na disciplina de Habilitação Séries Iniciais III, do Curso de Pedagogia da Faculdade de Educação (FaE), da Universidade Federal de Pelotas (UFPel), no sul do Brasil. A pesquisa foi realizada a partir da análise de um corpus de dados coletados em um dos semestres acadêmicos no qual essa prática foi implementada.

Minha percepção era de que tal prática potencializava os processos de aprendizagem dos estudantes, além de influenciar no desenvolvimento de algumas de suas habilidades intelectuais. Como acredito que os docentes necessitam refletir sobre suas atividades de ensino e avaliá-las criteriosa e sistematicamente - não bastando apenas que as percebam mal ou bem sucedidas - resolvi examinar minha metodologia de trabalho com textos para, além de avaliá-la, poder entendê-la e analisar a contribuição que pode fazer para o ensino universitário. Esta pesquisa se inscreve, então, na perspectiva proposta por Zeichner \& Diniz-Pereira (2005). Eles consideram que os conhecimentos produzidos por professores que investigam suas próprias práticas podem: a) beneficiar, diretamente, a prática de outros profissionais; b) serem incorporados em cursos de formação docente inicial e/ou continuada; e c) fornecer subsídios para políticas educacionais.

Antes de apresentar a avaliação da prática de trabalho com textos que se constitui no foco deste trabalho, penso ser importante fornecer algumas informações acerca de sua origem, bem como descrevê-la.

\section{As origens da prática desenvolvida}

Sempre atribuí importância ao trabalho com textos em minha prática docente, iniciada na FaE/UFPel em disciplinas da área de Psicologia da Educação. Essa importância decorreu, em grande parte, das discussões e dos trabalhos realizados em conjunto com meus colegas ${ }^{1}$, durante os quais buscávamos maneiras eficientes de levar os estudantes a fazer uso dos textos acadêmicos como algo mais do que simples fontes de informação função esta implícita no modelo pedagógico dito tradicional, ainda encontrado em larga escala em todos os níveis de ensino, no Brasil. Tal modelo é centrado na idéia de que ensinar é simplesmente transmitir informações que podem ser transferidas, diretamente, da boca do professor, ou do livro, para a mente dos estudantes. Ele traz subentendida a concepção de que o 
conhecimento é como um pacote de conteúdos pronto para ser recebido por um aprendiz passivo (Mizukami, 1986; Becker, 1993).

Esse modelo pedagógico tradicional vem persistindo através dos anos, apesar de receber um sem-número de críticas. A avaliação dos efeitos dos diferentes tipos de práticas pedagógicas vem mostrando, há bastante tempo, que a proposta de ensino tradicional não tem obtido o sucesso desejado (Becker, 1993; Castanho, 2001; Cunha, 1989, 1998; Freire \& Shor, 1987; Mizukami, 1986; Pimenta \& Anastasiou, 2002). Fundamentada no modelo da racionalidade técnica e na idéia de que tudo o que aprendemos é fruto exclusivo de nossa percepção, tal proposta negligencia a atividade do aprendiz durante o ato de aprendizagem. Não consegue, portanto, responder adequadamente aos propósitos de desenvolver nos estudantes uma forma crítica de pensar e dialogar com o conhecimento - o que considero de vital importância. Por essas razões, em oposição a esse modelo tradicional, tentei desenvolver uma forma de trabalho que lhe fosse alternativa, tentando maximizar a possibilidade de os textos atuarem como mediadores de atividades de pensamento, em adição a sua função informativa. Nesse sentido, considero que a prática que aqui avalio apresenta um caráter inovador, apesar das atividades desenvolvidas não se constituírem em novidades. Essa prática - que combina a elaboração de resumos dos textos com o estabelecimento de relações entre seu conteúdo e outras informações ou experiências - demanda dos estudantes uma atitude ativa, gerando envolvimento com a disciplina. Eles necessitam, efetivamente, ler os textos apontados e deles se apropriar para realizar a tarefa solicitada.

Abordo a utilização de textos, e a aprendizagem que a deve acompanhar, desde a perspectiva da apropriação do conhecimento, ou seja, aquela que entende a aprendizagem como um processo "no qual os seres humanos transformam em seus o mundo de objetos e fenômenos [...] que estão ao seu redor" (Leontiev, 1981: 422). Essa perspectiva, que se embasa em Vygotsky, Leontiev, Luria e demais adeptos da Psicologia Sócio-Histórica, está centrada em um pressuposto epistemológico que enfatiza a importância da interação do aprendiz com o objeto da aprendizagem - e dos diferentes aprendizes entre si - para que se produza o conhecimento. Neste sentido, o sujeito da aprendizagem é, necessariamente, um ser ativo: ele precisa interagir com os conteúdos a serem aprendidos e ir deles se apropriando, 
mediado por ferramentas e por outras pessoas que já tenham esses conteúdos melhor internalizados (Daniels, 2001). Nas situações de ensino formal, essa mediação é realizada, respectivamente, pelos textos, pelos professores - com seus recursos pedagógicos - e pelos colegas.

Essa perspectiva que adoto considera essencial que os estudantes entrem em contato direto com os textos dos autores cujas idéias pretendo que conheçam e internalizem, pois acredito que os professores jamais podem ensinar tudo o que esses textos contém, em aulas expositivas, por mais que se esmerem. Eles podem fazer um resumo de tais conteúdos, expor as interpretações que elaboraram, bem como as inter-relações que estabeleceram a partir do diálogo que eles próprios mantiveram com os textos. Mas isso não esgota as potencialidades desses textos. Eles necessitam ser trabalhados pelos próprios estudantes.

Nas escolas, em geral, os estudantes não são incentivados a estabelecer diálogos com o material escrito que lêem. Conforme observou Freire (1998), os estudantes são levados a apassivar-se aos textos, sem que se fomentem esses possíveis diálogos. O compartilhamento de opiniões, as discussões, as disputas de idéias não são produzidas quando a leitura de um texto visa apenas à recepção acrítica de determinados conteúdos pré-fixados (fomentada, provavelmente, pela necessidade de serem apenas "devolvidos" tal e qual foram expostos pelos autores, como costuma ser solicitado nas provas).

Não se pode pensar que os estudantes, mesmo frente a uma atividade que induz uma atitude passiva, deixem de interagir ativamente com as informações que lhes são apresentadas. Isso acontece, em maior ou menor escala, de acordo com o interesse e/ou a personalidade de cada um. Entretanto, minha experiência mostra que os estudantes, em geral, tendem a abordar os textos a partir de um tipo de leitura superficial, ou inspecional, isto é, "rápida, horizontal, que se faz para tomar conhecimento do conteúdo geral do texto" (Souza \& Carvalho, 1995, p. 62). Desse modo, assumem uma posição de escuta, de simples recepção, porque é mais cômoda, não exige esforço, pensamento, raciocínio, discussão. Tal comportamento pode, então, passar a ser legitimado e universalizado, se os professores não se opuserem a ele. Mesmo quando se quer combatê-lo, solicitando aos estudantes que se apropriem ativamente dos textos, nota-se que, não raro, eles não sabem 
como, ou não se dispõem a fazê-lo, principalmente quando os textos são considerados densos, difíceis, áridos ou desinteressantes. Assim, penso que não se pode confiar que a simples indicação de textos para leitura possa levar a uma significativa apropriação do conhecimento que contém.

As pesquisas sobre professores considerados de sucesso apontam para práticas que estimulam, sistematicamente, o duvidar epistemológico entre os estudantes (Castanho, 2001; Cunha, 1998). Esse é um ponto fundamental no tipo de trabalho com textos que aqui descrevo e avalio. Nele, tento fazer com que os estudantes desenvolvam um posicionamento crítico frente ao que leram e percebam a importância de compartilhar e discutir suas opiniões, criando um clima dialógico e democrático na sala de aula.

\section{Descrição da prática investigada}

A prática investigada - que denominei de "Elaboração de Sucos e Teias de textos" - vem sendo utilizada no Curso de Pedagogia da UFPEL, desde 2001, em diversas disciplinas. As turmas desse Curso são formadas por aproximadamente 45 estudantes - em sua grande maioria, do sexo feminino, com idade média em torno de 25 anos e pertencentes aos extratos médio e baixo da classe média.

A elaboração dos Sucos e Teias é uma tarefa que deve ser realizada a partir dos textos principais que fundamentam as disciplinas. Constitui-se em tarefa individual, elaborada por escrito, após a leitura de cada texto e trazida para a sala de aula no dia marcado para a discussão de seu conteúdo. Sua periodicidade varia conforme o decorrer da disciplina e o tempo necessário para que as estudantes se apropriem satisfatoriamente (tanto do seu ponto de vista, quanto do meu) dos conteúdos apresentados em cada texto.

A tarefa, então, compõe-se de duas partes:

a) O Suco, que é uma descrição breve do conteúdo do texto, uma espécie de síntese, cujo nome lhe foi atribuído porque se caracteriza, necessariamente, como algo condensado, como um sumo concentrado de uma fruta. Ele deve informar, em poucas "gotas" (meia página, aproximadamente) o que a estudante entendeu desse conteúdo. Tal exercício, além de fomentar a compreensão do texto, serve para "catalogá-lo", por assim dizer. 
Os Sucos poderão ser utilizados para orientar futuras pesquisas bibliográficas ou estudos que visem fundamentar as práticas que as estudantes necessitem desenvolver. Eles ajudam a evitar que os conteúdos das leituras realizadas caiam no esquecimento.

2) A Teia é constituída pelas relações dialógicas que a estudante estabeleceu entre o conteúdo do texto lido e os de outros textos, idéias e experiências. Ela é, então, a explicitação das relações entre idéias, informações, sentimentos, experiências estabelecidas por quem leu o texto, semelhante à teia produzida por uma aranha, com suas interconexões. A Teia deve ocupar, também, aproximadamente, meia página.

Em sala de aula, no dia previsto para a discussão de um determinado texto, alguns Sucos e Teias são lidos e discutidos ${ }^{2}$, juntamente com o estabelecimento de um diálogo mais amplo em que professora e estudantes apresentam seus entendimentos tanto a respeito do todo, como de tópicos específicos desse texto. Ali, mediante diálogos, as dúvidas e as dificuldades de compreensão são abordadas e discutidas.

A discussão inicia-se sempre com as impressões gerais das estudantes sobre o que foi lido e sobre o grau de dificuldade e de interesse suscitados. As contribuições voluntárias são valorizadas, mas também se incentivam as estudantes menos participativas a se manifestarem, para que o entendimento de todas possa ser compartilhado, discutido e melhorado. Durante a discussão, as estudantes podem (e devem) escrever, na própria folha em que estão seus Sucos e Teias, comentários, correções e novas informações que a discussão, porventura, tenha trazido para complementar/modificar sua tarefa. Ao final da aula, os trabalhos são recolhidos para uma breve análise posterior, já que considero serem suficientes as "correções", complementações e elaborações realizadas durante a discussão em aula. Ao ler as tarefas, teço comentários por escrito quanto a sua forma e adequação.

Especialmente em turmas de graduação, constata-se que os estudantes, em geral, não realizam as leituras indicadas e, entre os que as realizam, muitos fazem simplesmente uma leitura superficial (inspecional) dos textos. Tal comportamento inviabiliza aulas cujo desenrolar é baseado na discussão do que deveria ter sido lido, com o objetivo de potencializar a 
compreensão do assunto enfocado, além de relacioná-lo com outros conteúdos (Wells, 2001). Assim, a obrigatoriedade da leitura para a elaboração dos Sucos e das Teias garante que a aula programada seja efetivamente realizada e que os textos sejam discutidos. A elaboração e a pontualidade na entrega dos Sucos e das Teias são, assim, levados em conta na avaliação das estudantes e isso, de certa forma, faz com que elas realizem esses exercícios. É importante assinalar que o que valorizo é a realização dos exercícios e não propriamente o seu grau de 'correção'.

\section{Avaliando a prática}

Como já havia relatado anteriormente, percebia que a estratégia de trabalho com textos que adotava era capaz de render bons frutos, em termos de aprendizagens significativas para as estudantes. Isso também vinha ficando claro nas avaliações finais das disciplinas, realizadas ao final de cada semestre, em que as estudantes apresentavam suas opiniões oralmente. Entretanto, para que eu pudesse dispor de uma avaliação menos tingida pela minha subjetividade, pensei ser necessário realizar esta análise sistemática aqui apresentada. Para isso, foram utilizados dados colhidos por meio de avaliações escritas, realizadas por um grupo de 22 estudantes do Curso de Pedagogia, que se prontificaram a produzi-las, no semestre seguinte àquele em que a prática descrita foi realizada com sua turma. As avaliações foram realizadas durante um período de aula cedido por outra docente do Curso. Elas foram elaboradas a partir da seguinte solicitação: "Apresente sua opinião justificada sobre a atividade de leitura de textos seguida da tarefa de elaboração de Sucos e Teias, realizada na disciplina de Habilitações Séries Iniciais III". Propositadamente, o caráter da solicitação era amplo e nãodiretivo, para permitir que as avaliações das estudantes enfocassem os aspectos que considerassem mais significativos.

O fato de que somente a metade delas realizou tal avaliação não permite que se generalizem os resultados encontrados para toda a turma, embora eu considere os dados coletados importantes para revelar os efeitos da prática sobre as estudantes que participaram dessa avaliação. Esses dados, no entanto, devem ser analisados com o necessário cuidado.

Poder-se-ia levantar a hipótese de que as que não quiseram dar seus depoimentos agiram assim porque não consideraram positiva a experiência 
de trabalho com os Sucos e Teias e evitaram expressar essa opinião. Tal hipótese, entretanto, pode ser confrontada com o fato de os depoimentos terem sido colhidos após a avaliação formal das estudantes (atribuição das notas finais), por parte da professora, eliminando o medo de um possível risco de retaliação. Além disso, como se verá a seguir, esses depoimentos também apresentaram críticas negativas ao trabalho, o que contribui para sua confiabilidade. Pode-se supor, assim, que as estudantes que não participaram ou estavam ausentes no dia da coleta de dados ou não quiseram dar-se ao trabalho de escrever um texto (atividade que, geralmente, não costuma ser apreciada pelos estudantes).

Os dados coletados foram submetidos a um processo de análise de conteúdo - tipo análise temática (Minayo, 1992), na qual os temas gerais (categorias analíticas, provenientes da teoria) previamente estabelecidos para a análise eram: Categoria 1: avaliação geral da proposta; Categoria 2: efeitos da atividade sobre a aprendizagem de conteúdos; e Categoria 3: efeitos da atividade sobre habilidades intelectuais das estudantes. Os dados, ao serem examinados enfocando cada um desses temas, geraram subcategorias empíricas, que serão apresentadas adiante. Para ilustrá-las, ao longo da análise, incluí extratos dos depoimentos escritos pelas estudantes ${ }^{3}$.

\section{Os achados e sua análise}

\section{Avaliação geral da proposta}

A leitura dos depoimentos traz uma impressão geral de aprovação por parte das estudantes. Todos eles incluem pontos positivos, embora 16 incluam críticas ao trabalho realizado. Tais críticas foram baseadas, principalmente, nas dificuldades em realizar as tarefas (especialmente a Teia), na sua obrigatoriedade e no fato de envolverem procedimentos considerados cansativos e maçantes, como se observa nos extratos que seguem. Eles, entretanto, mostram também que as estudantes consideraram as tarefas úteis para a sua formação.

[...] acho muito chata essa tarefa, mas tenho consciência que é através desse "compromisso" que me empenho em ler e compreender os textos (Estudante 21). 
A realização de "sucos e teias" é importante para o desenvolvimento da nossa escrita, embora, muitas vezes, esse tipo de tarefa, que nos é solicitada, tornase uma "obrigação" e não uma "satisfação" (Estudante 24).

[...] acho um pouco chato e cansativo. Digo por mim, pois não tinha o hábito de ler e escrever muito e, às vezes, estas atividades [escrever sucos e teias] se tornavam um pouco difíceis, principalmente a "teia", na qual temos que fazer relações, ligações, com outros textos, com outras leituras. [...] sei que não adianta achar chato fazer estas atividades, pois tenho certeza que, se não fosse imposta, muita gente não faria, principalmente eu. [...] Acredito que devem continuar as "teias" e os "sucos", mas com menos freqüência (Estudante 7).

Os extratos acima exemplificam, principalmente, os pontos negativos da prática pedagógica avaliada, embora contenham, também, alguns pontos positivos. Estes ficarão evidentes no decorrer deste relato, embora eu queira aqui destacar dois extratos pela forma marcante com que apresentam esses pontos positivos:

Pessoalmente, hoje te diria que tranqüilamente usaria essa metodologia amanhã com meus alunos, pois os resultados superam as reclamações (Estudante 9).

[...] hoje considero indispensável para um bom entendimento e interpretação dos textos a realização do "suco" e da "teia" (Estudante 1).

Além das evidências provenientes dos depoimentos, é importante acrescentar o fato de que a realização dos Sucos e das Teias tem sido associada com a aprovação ao final no semestre, sugerindo que auxilia na aprendizagem das estudantes. No caso da turma em foco, as cinco estudantes reprovadas haviam deixado de realizar vários Sucos e Teias (embora tivessem tido a chance de entregá-los com atraso) ${ }^{4}$. Todas as aprovadas haviam realizado essas tarefas.

Outro fato a destacar, e que se reflete na avaliação geral da proposta, é que várias estudantes mencionaram que as atividades realizadas exerceram influência em outras disciplinas do curso e em seu próprio comportamento, como mostram os depoimentos a seguir:

Também saliento, para finalizar, que realizar estas tarefas tem contribuído, e muito, para adquirirmos mais responsabilidade, sem falar que esta técnica tem sido acatada por outros professores e, a partir desta disciplina, a temos realizado com mais facilidade (Estudante 2).

[...] fazer teias tornou-se um hábito que relaciona-se a textos e até mesmo na minha vida (Estudante 22). 
[...] até mesmo para estudar, eu uso meus sucos, me ajudou muito a ler os textos de outras disciplinas, porque sempre acabo fazendo um suco e compreendendo melhor o texto (Estudante 8).

Observações e contatos com meus colegas de trabalho confirmam essa informação sobre a adoção da proposta por alguns, sugerindo que eles também perceberam os efeitos positivo dessas atividades.

\section{Efeitos sobre a aprendizagem de conteúdos}

A análise desta categoria revelou que, na opinião das estudantes, a prática de leitura e elaboração de Sucos e Teias de textos possibilitou o seguinte, em termos de aprendizagem de conteúdos: a) compreensão em maior grau de profundidade e internalização mais eficiente; b) estabelecimento de interconexões com outros conteúdos anteriormente trabalhados e com experiências vivenciadas; e c) reflexão.

a) Compreensão em maior grau de profundidade e internalização mais eficiente

Esta subcategoria foi citada por 15 estudantes e nela foram incluídas as opiniões que indicavam percepções acerca do potencial da atividade para promover compreensão e interpretação, em profundidade, dos conteúdos dos textos estudados, bem como para levar a uma internalização desses conteúdos de forma mais eficiente, auxiliando também na sua retenção.

Por meio destas atividades, tive a oportunidade de aprender de uma forma mais aprofundada os temas discutidos em aulas (Estudante 5).

[...] analisando agora, fora do contexto, vejo que contribuíram muito, pois fazendo teias, é mais fácil de compreender os textos novos, relembrar e associar com os antigos (Estudante 6).

Foi bom pelo fato que nos obrigou a ler o texto toda a semana e isso nos fez acompanhar a matéria mais tranqüilamente, podendo tirar nossas dúvidas na aula e assim entendendo melhor o conteúdo (Estudante 12).

[...] me levou a muito mais do que uma simples leitura, a uma interpretação do que estava lendo [...] (Estudante 22). 


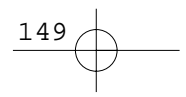

b) Estabelecimento de interconexões com outros conteúdos anteriormente trabalhados e com experiências vivenciadas

Opiniões classificadas nesta subcategoria apareceram em 12 depoimentos, sugerindo que essas estudantes perceberam, na atividade realizada, a possibilidade de promover o estabelecimento de inter-relações entre diferentes textos, conteúdos de diferentes disciplinas e vivências aspecto importante para a apropriação de conteúdos acadêmicos:

A teia é uma atividade reflexiva, que leva a relações com outros textos, formando "pontes" entre os conhecimentos adquiridos (Estudante 14).

Quando fazemos uma "boa teia", demonstramos que conseguimos compreender o texto, internalizá-lo e relacioná-lo com outras leituras feitas anteriormente, ou com experiências vividas (Estudante 23).

No que se refere às "teias", percebemos a importância destas porque é o momento em que temos a oportunidade de expormos várias idéias, interligarmos assuntos dos diversos tipos (Estudante 24).

\section{c) Reflexão}

Nos depoimentos de 7 estudantes, aparecem menções à possibilidade de reflexão sobre os novos conteúdos, veiculados na disciplina, oferecida pela atividade proposta, como mostram os exemplos:

Considero muito importante a tarefa de estabelecer teias porque nos faz refletir acerca dos conhecimentos, conceitos e saberes que adquirimos (Estudante 1).

[...] ao fazer o suco iremos retomar nossa leitura, verificando se não ficou faltando nada (Estudante 7).

[...] a teia faz a gente refletir e isso nos "desequilibra". [...] temos que refletir sobre eles [assuntos] e tirar nossos próprios sucos e teias. [...] Obrigação ou não, é uma boa forma de fazer com que possamos ler. E, principalmente, $o$ objetivo não é só ler, mas sim pensar, e isso é fundamental (Estudante 19) (grifos da estudante).

\section{Efeitos sobre habilidades intelectuais das estudantes}

Esta categoria desdobrou-se em duas subcategorias que envolvem o desenvolvimento e o aprimoramento de: a) expressão escrita; b) outras habilidades relacionadas aos processos de pensamento. 


\section{a) Desenvolvimento e aprimoramento da expressão escrita}

Presente nos depoimentos de 7 estudantes, esta subcategoria expressa suas opiniões sobre um ganho não diretamente relacionado com a apropriação de conteúdos acadêmicos, mas, em minha opinião, de igual importância para a sua formação: a capacidade de se expressar adequada e corretamente por escrito.

Considero o suco importante para o crescimento da escrita e aprimoramento (Estudante 14).

O trabalho com "sucos" para mim foi proveitoso. Ele é um exercício de síntese que ajuda a tornar a escrita objetiva e, ao mesmo tempo, completa (Estudante 12).

Portanto, "sucos e teias" deverão fazer sempre parte desta disciplina porque irão proporcionar mais "confiança" aos escrevermos, ou melhor, nos expressarmos (Estudante 24).

Tenho muita dificuldade em escrever pouco e acredito que os "sucos" já me ajudaram bastante neste problema. Se continuar a fazê-los, tenho certeza que vou conseguir ser mais objetiva nas minhas escritas, quando necessário (Estudante 17).

\section{b) Desenvolvimento de outras habilidades relacionadas aos processos de pensamento}

Os depoimentos incluídos nesta subcategoria mostram que algumas estudantes perceberam, em si mesmas, o desenvolvimento e o aperfeiçoamento de diferentes habilidades cognitivas, tais como: habilidade de sintetizar idéias e de reconhecer o foco dos textos lidos, agilidade mental, habilidade de estudar e aprender com eficiência e reconhecimento das próprias dificuldades (metacognição ${ }^{5}$ ).

Em relação aos sucos, tenho aprendido a resumir não só pequenos textos, mas também livros, através dessa tarefa. Sinto-me mais segura ao ler e saber quais os pontos principais que devem ser comentados. Também aprendi a explicar melhor estes pontos (Estudante 2).

Sob o meu ponto de vista, a experiência de realizar sucos e teias é extremamente importante pois [...] aprimoramos [...] nossa capacidade de síntese (Estudante 10).

[...] até mesmo para estudar, eu uso meus sucos. Me ajudou muito a ler os textos de outras disciplinas, porque sempre acabo fazendo um suco e compreendendo melhor o texto (Estudante 8).

[...] amplia o saber e aguça a "agilidade" do pensamento e a capacidade de aprendizagem (Estudante 14). 
Essa atividade permite que eu perceba as minhas dificuldades podendo assim nos próximos melhorá-las (Estudante 5).

Resumindo foi importante, foi válida e principalmente me proporcionou um crescimento intelectual muito grande (Estudante 22).

Os dados apresentados acima sugerem que a proposta de trabalho avaliada tem potencial para produzir benefícios ao processo de aprendizagem e desenvolvimento de estudantes que nela se envolvem. Dito isso, penso ser importante analisar as origens e as razões de tais benefícios.

\section{Entendendo e teorizando sobre a prática desenvolvida}

Considero que a prática de trabalho com textos, aqui descrita e avaliada, envolve processos mentais tais como análise, síntese, abstração, geração e teste de hipóteses, comparação, inferência, generalização e metacognição. Tais processos são apontados como fundamentais para a aprendizagem de conceitos por autores como Vygotsky (1986) e Barth (1994), por exemplo. Mas, se pode perguntar: como os Sucos e as Teias propiciam tais processos?

Os Sucos demandam dos estudantes que analisem e, após, sintetizem as idéias dos textos lidos, realizando abstrações que expressam as idéias gerais dos mesmos (não deixando também de se constituir em hipóteses, acerca do seu significado geral, a serem testadas durante as discussões em aula). Souza \& Carvalho (1995) explicam que a compreensão de um texto depende da realização desses processos de análise, síntese e comparação. Eles argumentam que "analisar é dividir um conjunto a fim de descobrir e revelar os elementos de seu todo, bem como especificar as relações desses elementos entre si" (p.19). Isso implica na separação das idéias principais das secundárias, na reflexão sobre as mesmas e no confronto do texto com outros que abordam o mesmo assunto. Sintetizar, por outro lado, significa "pôr junto" (Souza \& Carvalho, 1995) e isso requer o entendimento do conteúdo do material escrito, centrado em suas idéias principais, ou núcleos semânticos. Segundo Paulo Freire (1998: 45), é o procedimento de síntese que garante a produção do que denominou "inteligência" do texto. O autor explica que, quando o leitor alcança criticamente essa "inteligência", ele se torna co-autor do texto, não falando dele apenas como quem simplesmente o leu, mas como quem o trabalhou e re-trabalhou até que essa "inteligência", que não estava 
ali imobilizada à sua espera, fosse produzida. Freire afirma que isso é o que torna o ato de ler ao mesmo tempo difícil e apaixonante.

Os processos de inferência, comparação e generalização, aparecem também na elaboração das Teias, melhor qualificando a internalização e retenção na memória dos novos conhecimentos, para uso futuro, além de conferir-lhes significado. Esta alegação sustenta-se nas idéias de Anderson (1980). Esse autor explica que as informações que armazenamos em nossa memória de longo-prazo nem sempre estão disponíveis para recordação. Não temos acesso direto a qualquer dado que não esteja em nossa memória de curto prazo (memória de trabalho) e, se quisermos lembrar do que está guardado naquela, necessitamos ativá-la e trazer os elementos lá estocados para esta. Baseado em inúmeras investigações a respeito da capacidade de recordação de informações por parte dos seres humanos, Anderson afirma que existem evidências de que as que tiverem sido "melhor aprendidas", isto é, codificadas de maneira mais elaborada na memória de longo prazo, podem ser mais rapidamente ativadas. Ele complementa tal idéia dizendo que as informações mais eficientemente recordadas são aquelas que foram armazenadas na forma de redes, isto é, em núcleos de significados interconectados, que lhes disponibilizam diferentes vias de acesso.

A essa idéia sobre a estruturação da memória pode-se acrescentar o que Vygotsky (1986) escreveu acerca da importância de promover a interação dos novos conteúdos que se pretende internalizar com os conhecimentos que já foram apropriados, estruturando-os em redes hierárquicas e lógicas, para a aprendizagem. Ele explicava que os conceitos aprendidos não ficam na mente da pessoa "como ervilhas em um saco, sem nenhuma ligação entre elas" (p.197). Se isso acontecesse, não seria possível realizar nenhuma operação intelectual que exigisse coordenação de pensamentos. Para Vygotsky, um conceito somente pode ser submetido à consciência e ao controle deliberado quando faz parte de um sistema e pode ser assim relacionado a outros conceitos. Além disso, ele salienta a necessidade de que o professor estabeleça relações entre o que denomina conceitos científicos (aqueles sistematizados e trabalhados na escola) com os conceitos espontâneos dos aprendizes (aqueles gerados pela experiência no mundo, não sistematizados). Isso traz sentido aos primeiros e evita que fiquem apenas em um nível teórico, desvinculado da vida (Vygotsky, 1998). 
Essas idéias indicam a importância de promover, ativamente, a construção de redes de conceitos, já que nossa experiência tem mostrado que os estudantes, em geral, não criam essas redes por conta própria. Eles parecem manter os conteúdos aprendidos em cada disciplina em separado, compartimentalizados, como se não tivessem relação entre si. Concordo com Cardoso (1999: 61) quando afirma que "todo texto é um intertexto, no sentido de que outros textos estão presentes nele, em níveis variados, podendo ser reconhecidos ou não". Assim, ao solicitar que as estudantes reflitam acerca das relações que estabelecem entre o texto lido e os diversos outros "textos"6 que estão em sua memória - resultantes de leituras, de ensino, ou de experiências - tenho a intenção de gerar nelas a necessidade de refletir sobre o que foi lido, comparando informações e experiências novas e antigas, julgando semelhanças e/ou disparidades, fazendo generalizações.

Foi salientada, pelas estudantes, a importância dos exercícios de escrita realizados - atividades que integram, de maneira substantiva, a elaboração dos Sucos e das Teias. Elas perceberam que esses exercícios constantes levaram-nas a estruturar suas idéias de maneira mais coerente, bem como as auxiliaram a preservar os conteúdos estudados, que poderão ser recordados mais facilmente quando forem necessários. Essa relação entre o exercício da escrita e a aprendizagem foi apontada por Bereiter \& Scardamalia (1987, apud Wells, 2001). Os autores explicam que a composição de um texto (e eu acrescentaria que isso se aplica, principalmente, aos textos acadêmicos, teóricos) demanda clareza, na medida em que esse texto tenha a função de comunicar idéias na ausência de um interlocutor direto. Se o conteúdo a ser exposto no texto não estiver claro para o escritor, então ele não poderá expressá-lo com a necessária clareza.

Nos livros dedicados ao estudo da aprendizagem, é muito mais comum encontrar o tema do desenvolvimento de funções mentais sendo discutido em relação à infância do que à idade adulta. A pouca ênfase dada à possibilidade de desenvolvimento do instrumental intelectual dos adultos poderia levar à conclusão de que esse desenvolvimento é algo que não necessita atenção e investigação e que as mentes dos adultos (pelo menos daqueles classificados como "normais") já estão prontas, não havendo nelas nada a ser modificado ou aperfeiçoado (Araújo, 2004). Tenho como pressuposto que isso não é 
assim. Tanto pessoas adultas como crianças apresentam potencial para a aprendizagem e, como explicava Vygotsky (1986), a aprendizagem (principalmente a escolar) precede e influencia o desenvolvimento mental dos seres humanos.

Segundo Smith (1982), o traço característico do desenvolvimento psíquico é a acumulação, não só de noções, mas de modos e ações intelectuais, que se vão aperfeiçoando com o exercício. Graças à formação desses modos de ações, e à consciência a respeito dos mesmos, o ser humano tem a possibilidade de usá-los voluntariamente para a execução de novas tarefas cognitivas. Para explicar melhor essa idéia, podemos nos valer do que escreveram Bogoyavlensky \& Menchinskaya (1991: 46): "o processo de aprendizagem muda não só o que se pensa conscientemente, mas também os modos como se produz esta reflexão, ou seja, o processo mental implicado". A aprendizagem desenvolve formas de atividade analíticosintéticas (nas quais se incluem as já citadas capacidades de realizar abstrações e generalizações) que modificam a organização do pensamento verbal. Seu exercício faz com que tais atividades se convertam em hábitos que, mais tarde, se manifestem com liberdade e facilidade. Assim, penso ser válido supor que a prática de trabalho com textos analisada tenha ocasionado também desenvolvimento dos processos intelectuais das estudantes, embora seus depoimentos estejam principalmente centrados nos efeitos da prática desenvolvida sobre a aprendizagem de conteúdos e capacidade de expressão escrita.

Por fim, ainda em relação ao desenvolvimento cognitivo, parece importante comentar que os depoimentos de algumas estudantes revelaram que elas tomaram consciência de seus estilos cognitivos e dos pontos fortes e fracos relacionados com suas formas de aprender, realizando um processo de metacognição. Segundo Figueira (s.d.), as pessoas que apresentam habilidades metacognitivas bem desenvolvidas são capazes de compreender melhor e planejar mais efetivamente a execução de tarefas. Elas também são capazes de aplicar e alterar, conscientemente, estratégias executivas, bem como avaliar seu próprio processo de execução, elementos chave no processo de aprender a aprender. 


\section{Comentários finais}

A pesquisa realizada sugere que as práticas pedagógicas balizadas pelo desenvolvimento do pensar podem trazer benefícios, no caso para estudantes universitários. Isso pode ser alcançado ao associar à leitura de textos - atividade contumaz, nesses níveis de ensino - atividades de reflexão, discussão e escrita sobre suas idéias principais e relações com outros textos, informações e experiências. Tais atividades apresentam o potencial de promover, nos estudantes, um grau mais elevado de compreensão e apropriação dos conteúdos veiculados pelos textos, um melhor armazenamento desses conteúdos na memória de longo prazo, assim como o desenvolvimento de habilidades cognitivas transferíveis para outras situações de ensino e aprendizagem.

As práticas adotadas por uma instituição de ensino sempre revelam o controle social que é exercido sobre ela e as ideologias ali subjacentes (Cury, 1989; McLarem, 1991). Por esta razão, acredito que todos os professores necessitam examinar seu trabalho no sentido de não deixar que tais ideologias passem despercebidas. Penso que a prática analisada apresenta potencial para superar as metodologias tradicionais de ensino, que incentivam as relações hierárquicas e o monólogo, visando apenas à incorporação reprodutiva e passiva dos conteúdos das disciplinas, sem preocupação com o desenvolvimento dos estudantes em termos cognitivos e/ou críticos. Esse tipo de desenvolvimento é fundamental em uma sociedade, como a brasileira, marcada pela reprodução de idéias, pela ausência de reflexão crítica e pela dificuldade de expressão (principalmente na forma escrita).

\section{Notas}

1 Em especial a Prof. Solange Pino de Barros Coelho, com quem compartilhei experiências de ensino extremamente enriquecedoras. A ela agradeço pelas aprendizagens proporcionadas, além das contribuições para este texto.

2 Como as turmas são, em geral, grandes, torna-se impossível a apresentação oral do trabalho por todas as estudantes.

3 Os depoimentos são apresentados respeitando a forma como foram escritos. Os grifos são de minha autoria. 
4 Considero necessário que os textos selecionados para uma disciplina sejam todos lidos e refletidos pelas estudantes, mesmo depois das discussões realizadas em aula. Por esta razão, penso ser essencial a entrega dos Sucos e das Teias, mesmo com atraso.

5 A metacognição pode ser entendida como o conhecimento acerca do que se conhece, bem como a capacidade de avaliar e controlar o que foi aprendido (Figueira, s.d.; Wells, 2001; Ribeiro, 2003; Portilho, 2004).

6 Aqui, uso a palavra texto em um sentido figurado.

\section{Referências}

ANDERSON, John. R. (1980). Cognitive Psychology and its Implications. San Francisco: W.H. Freeman and Company.

ARAÚJO, Elaine S. (2004). A aprendizagem e o desenvolvimento profissional docente sob as luzes da perspectiva histórico-cultural. Comunicação apresentada no XII Encontro Nacional de Didática e Prática de Ensino (ENDIPE), Curitiba.

BARTH, Britt-Mari (1994). O Saber em Construção: para uma Pedagogia da Compreensão. Lisboa: Instituto Piaget.

BECKER, Fernando (1993). Modelos pedagógicos \& modelos epistemológicos. Paixão de Aprender, Porto Alegre, n.5, pp.18-23.

BOGOYAVLENSKY, D. N. \& MENCHINSKAYA, Natalie A. (1991). Relação entre aprendizagem e desenvolvimento psicointelectual da criança em idade escolar. In A. Leontiev; L. Vygotsky \& A. Luria (orgs.) Psicologia e Pedagogia. São Paulo: Moraes.

CARDOSO, Silvia. H. B. (1999). Discurso e Ensino. Belo Horizonte: Autêntica.

CASTANHO, Maria E. (2001). Sobre professores marcantes. In S. Castanho \& M. E. Castanho (Orgs.), Temas e Textos em Metodologia do Ensino Superior. Campinas, SP: Papirus, pp.153-163.

CUNHA, Maria I. da (1989). O Bom Professor e Sua Prática. Campinas, SP: Papirus.

CUNHA, Maria I. da (1998). O Professor Universitário na Transição de Paradigmas. Araraquara, SP: JM Editores.

CURY, Carlos R. J. (1989). Educação e Contradição: Elementos Metodológicos para uma Teoria Crítica do Fenômeno Educativo. São Paulo: Cortez/Autores Associados.

FIGUEIRA, A. P. C. (s.d.). Metacognição e seus contornos. Disponível em http://www. campus-oei.org/revista/de los lectores/446Couceiro.pdf. Acesso em 11/06/2005.

DANIELS, Harry (2001). Vygotsky e a Pedagogia. São Paulo: Loyola.

FREIRE, Paulo (1998). Professora Sim, Tia Não: Cartas a quem Ousa Ensinar. São Paulo: Olho d'água.

FREIRE, Paulo \& SHOR, Ira (1987). Medo e Ousadia: o Cotidiano do Professor. Rio de Janeiro: Paz e Terra. 


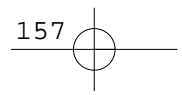

LEONTIEV, Alex. N. (1981). Problems of Development of the Mind. Moscow: Progress Publishers.

McLAREN, Peter (1991). Rituais na Escola: em Direção a uma Economia Política de Símbolos e Gestos em Educação. Petrópolis: Vozes.

MINAYO, Maria C. de S. (1992). O Desafio do Conhecimento: Pesquisa Qualitativa em Saúde. São Paulo: Hucitec/Abrasco.

MIZUKAMI, Maria da G. N. (1986). Ensino: as Abordagens do Processo. São Paulo: E.P.U.

PIMENTA, Selma G. \& ANASTASIOU, Léa das G. C. (2002). Docência no Ensino Superior. São Paulo: Cortez.

PORTILHO, Evelise M. L. (2004). A Aprendizagem na Universidade: os Estilos de Aprendizagem e Metacognição. Comunicação apresentada no XII Encontro Nacional de Didática e Prática de Ensino (ENDIPE), Curitiba.

RIBEIRO, Célia (2003). Metacognição: um apoio ao processo de aprendizagem. Psicologia: Reflexão e Crítica, vol.16, no.1, pp.109-116.

SMITH, Frank (1982). Understanding Reading. New York: Holt, Rinehart and Winston.

SOUZA, Luiz M. de \& CARVALHO, Sérgio W. de (1995). Compreensão e Produção de Textos. Petrópolis: Vozes.

VYGOTSKY, Lev S. (1986). Thought and Language. Cambridge: MIT Press.

VYGOTSKY, Lev S. (1998). A Formação Social da Mente. São Paulo: Martins Fontes.

WELLS, Gordon (2001). Indagación Dialogica: hacía una Teoría y una Práctica Socioculturales de la Educación. Barcelona: Paidós.

ZEICHNER, Kenneth M. \& DINIZ-PEREIRA, Júlio E. (2005). Pesquisa dos educadores e formação docente voltada para a transformação social. Cadernos de Pesquisa, vol. 35, no. 125, pp.63-80. 


\section{WORKING WITH TEXTS AT UNDERGRADUATE LEVEL}

This paper has the objective of presenting, discussing and evaluating a teaching activity proposal for the undergraduate level. Such proposal is based mainly on reading and discussing texts, demanding an active posture on the part of students. It has been developed as an alternative to traditional pedagogical activities which usually use texts as mere sources of information. The proposal is supported by Socio-Historic Psychology and has been implemented at the Federal University of Pelotas (Brazil). It was analyzed through written evaluations that contained the opinions of Pedagogy students about it. The evaluations underwent a process of thematic analysis and indicated that the proposal, in spite of some criticism (related mainly to the effort necessary to develop the assigned tasks), has been considered successful. The students reported that, through the activities they have carried out, they were able to: understand the texts in a more profound manner and internalize their content more efficiently; establish interconnections with other information previously learned and/or life experiences; and reflect upon what they have learned. They also reported developing and improving their written expression abilities and other abilities related to thinking processes.

Keywords

Working with texts; Teaching at undergraduate level; Learning; SocioHistorical Psychology 


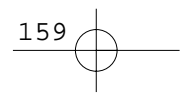

\section{LE TRAVAIL AVEC DES TEXTES DANS L'ENSEIGNEMENT SUPERIÉUR}

\section{Résumé}

Ce texte a comme but présenter, réflechir et évaluer au sujet d'une proposition d'activité didactique dans l'enseignement supérieur, fondée surtout à la lecture et discussion de textes qui exigent une position active des étudiants. Cette proposition a été développée comme une alternative aux activités didactiques traditionnelles qui, en général, utilisent les textes seulement comme une source d'informations. La proposition est soutenue par la Psychologie SocioHistorique et se développe à l'Université Fédérale de Pelotas (Brésil). Son analyse a été faite par des évaluations écrites qui ont pris les opinions d'étudiantes d'une classe de Pédagogie sur la proposition. Les évaluations ont souffert un processus d'analyse thématique, indiquant que la proposition a été évaluée positivement par les étudiantes, malgré quelques critiques (surtout par rapport aux efforts nécessaries pour déveloper les tâches). Les élèves ont rapporté qu'au moyen de ces activités, elles ont pu: comprendre plus profondement les textes lus et apprendre leur contenu d'une manière plus efficiente; établir interconnexions avec d'autres contenus travaillés auparavant et/ou avec des expériences vécues; réflechir sur tout ce qu'elles ont appris, en plus de développer et améliorer leurs habiletés d'expression écrite et encore d'autres habiletés liées aux processus de pensée.

Mots-clé

Travail avec des textes; Enseignement superiéur; Apprentissage; Psychologie Socio-Historique 